University of Wollongong

Research Online

Australian Institute for Innovative Materials -

Papers

Australian Institute for Innovative Materials

$1-1-2016$

MoS2 with an intercalation reaction as a long-life anode material for lithium ion batteries

Zhe $\mathrm{Hu}$

University of Wollongong, zh865@uowmail.edu.au

Qiannan Liu

University of Wollongong, q1953@uowmail.edu.au

Weiyi Sun

Nankai University

Weijie Li

University of Wollongong,w1347@uowmail.edu.au

Zhanliang Tao

University of Wollongong, ztao@uow.edu.au

See next page for additional authors

Follow this and additional works at: https://ro.uow.edu.au/aiimpapers

Part of the Engineering Commons, and the Physical Sciences and Mathematics Commons

Research Online is the open access institutional repository for the University of Wollongong. For further information contact the UOW Library: research-pubs@uow.edu.au 


\title{
MoS2 with an intercalation reaction as a long-life anode material for lithium ion batteries
}

\begin{abstract}
MoS2 with expanded layers was synthesized and characterized as an anode material for lithium ion batteries in an ether-based electrolyte by cutting off the terminal discharge voltage at $1.0 \mathrm{~V}$ to prevent a MoS2 conversion reaction. The as-prepared MoS2 achieved 96\% capacity retention even after 1400 cycles and showed good performance in a full cell with $\mathrm{LiCoO} 2$ as the counter electrode.
\end{abstract}

\section{Keywords}

long, life, anode, material, reaction, lithium, mos2, ion, batteries, intercalation

Disciplines

Engineering | Physical Sciences and Mathematics

\section{Publication Details}

Hu, Z., Liu, Q., Sun, W., Li, W., Tao, Z., Chou, S., Chen, J. \& Dou, S. (2016). MoS2 with an intercalation reaction as a long-life anode material for lithium ion batteries. Inorganic Chemistry Frontiers, 3 (4), 532-535.

\section{Authors}

Zhe Hu, Qiannan Liu, Weiyi Sun, Weijie Li, Zhanliang Tao, Shulei Chou, Jun Chen, and S X. Dou 


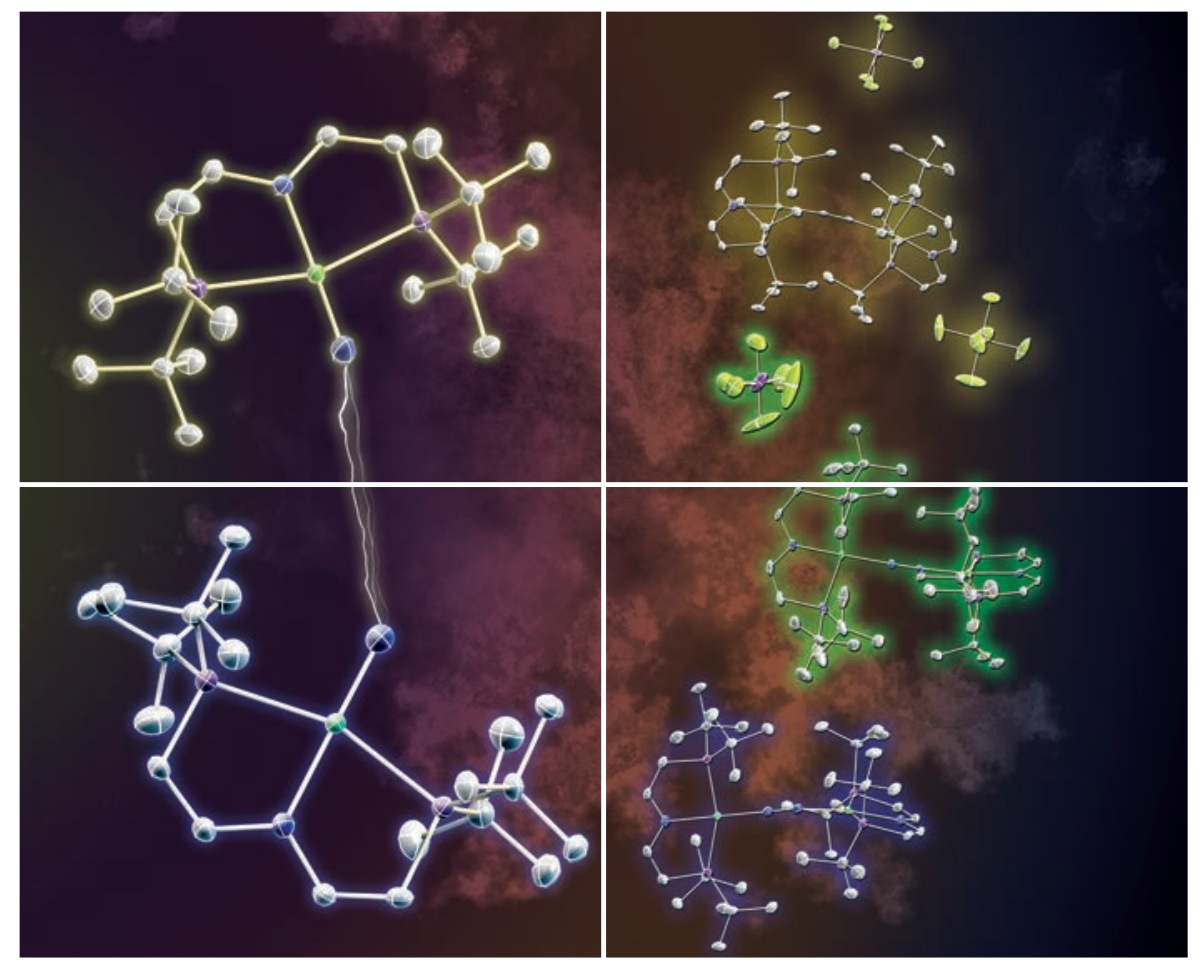

\section{INORGANIC}

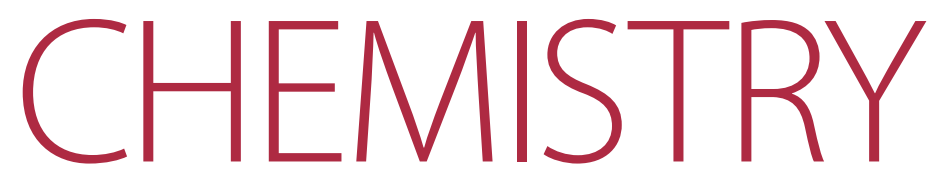

\section{FRONTIERS}




\section{RESEARCH ARTICLE}

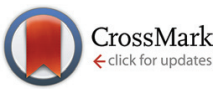

Cite this: Inorg. Chem. Front., 2016, 3, 532

Received 4th November 2015

Accepted 5th January 2016

DOI: $10.1039 / c 5 q i 00237 k$

rsc.li/frontiers-inorganic

\section{$\mathrm{MoS}_{2}$ with an intercalation reaction as a long-life anode material for lithium ion batteries $\dagger$}

\author{
Zhe Hu, ${ }^{a}$ Qiannan Liu, ${ }^{a}$ Weiyi Sun, ${ }^{b}$ Weijie Li, ${ }^{a}$ Zhanliang Tao, ${ }^{a, b}$ Shu-Lei Chou, ${ }^{* a}$ \\ Jun Chen ${ }^{\mathrm{b}, \mathrm{c}}$ and Shi-Xue Dou ${ }^{\mathrm{a}}$
}

Recently rechargeable batteries have attracted a large amount of attention, mainly because of their cyclability, as a sustainable power supply. ${ }^{1-3}$ Especially for rechargeable lithium ion batteries (LIBs), practical applications mostly facilitate social development. ${ }^{4,5}$ Among different kinds of electrode materials, $\mathrm{MoS}_{2}$ has become one of the most popular materials owing to its layered graphite-like structure. ${ }^{6-8}$ The weak van der Waals force between adjacent layers is easy to break by lithium ion insertion and a full conversion reaction provides a high specific capacity of $670 \mathrm{~mA} \mathrm{~h} \mathrm{~g}^{-1}$ (four-electron reaction). ${ }^{9-11}$ In order to achieve optimized electrochemical performances, the reaction mechanism of $\mathrm{MoS}_{2}$ cycling at $0.1-3.0 \mathrm{~V}$ has been widely discussed. ${ }^{12,13}$ In the first cycle, there is an intercalation process of $\mathrm{MoS}_{2}$ reacting with $\mathrm{Li}^{+}$to form $\mathrm{LiMoS}_{2}$, which accompanies a phase change from trigonal prismatic $\mathrm{MoS}_{2}$ $\left(2 \mathrm{H}-\mathrm{MoS}_{2}\right)$ to octahedral $\mathrm{MoS}_{2}\left(1 \mathrm{~T}-\mathrm{MoS}_{2}\right){ }^{10}$ As the interlayer spacing is much larger than that of graphite, this will introduce less of a volume change regarding the intercalation process. ${ }^{14}$ Then with continuous $\mathrm{Li}^{+}$intercalation, the structure of the layered $\mathrm{MoS}_{2}$ decomposes to Mo metal and $\mathrm{Li}_{2} \mathrm{~S}$. This step possesses large volume expansion $(\sim 103 \%)$ leading to electrode pulverization. ${ }^{15-17}$ Because the charge products can never return back to $\mathrm{MoS}_{2}$ again, the reaction mechanism of the following cycles is the reversible reaction between $\mathrm{Li}_{2} \mathrm{~S}$ and $\mathrm{S}$, just the same as that for $\mathrm{Li} / \mathrm{S}$ batteries. This presents the problem that $\mathrm{MoS}_{2}$ should also come across the

\footnotetext{
${ }^{a}$ Institute for Superconducting and Electronic Materials, Australian Institute for Innovative Materials, University of Wollongong, Innovation Campus, Squires Way, North Wollongong, NSW 2522, Australia. E-mail: shulei@uow.edu.au

${ }^{b}$ Key Laboratory of Advanced Energy Materials Chemistry (Ministry of Education), Nankai University, Tianjin, 300071, People's Republic of China.

E-mail: taozhl@nankai.edu.cn

${ }^{c}$ Collaborative Innovation Center of Chemical Science and Engineering, Nankai University, Tianjin, 300071, People's Republic of China

$\dagger$ Electronic supplementary information (ESI) available: Experimental section, XRD, TEM, and electrochemical characterization. See DOI: 10.1039/c5qi00237k
}

difficulties encountered in Li/S batteries, such as the severe capacity loss owing to the active material dissolution, the polysulfide shuttling effect, and the side reaction between polysulfides and the electrolyte. ${ }^{18-20}$ So it is urgent to find an appropriate method to solve the problems mentioned above.

The most effective method is the nano-size design together with carbon modification. ${ }^{21}$ The nano-size design would provide a short ion diffusion path, which will enhance the reaction kinetics. ${ }^{22}$ By coating with carbon, the active materials can be protected from the negative effect of the volume expansion and accelerate the surface electron transportation. Qiao and coworkers synthesized mesoporous $\mathrm{MoS}_{2}$ with expanded interlayers. The as-prepared product showed an initial capacity of $1052 \mathrm{~mA} \mathrm{~h} \mathrm{~g}{ }^{-1}$ and lasted for 100 cycles at $0.1 \mathrm{~A} \mathrm{~g}^{-1} .^{18}$ Although carbon coating leads to great improvement of $\mathrm{MoS}_{2} /$ $\mathrm{Li}$ batteries, the cycling performance is still hard to match to the need for commercialization, and the broadened voltage region $(0.1-3.0 \mathrm{~V})$ still suffers from safety issues like electrolyte decomposition, large volume change ( $203 \%$ after change), and the precipitation of lithium metal on the anode surface of LIBs. Thus to further improve the electrochemical performance of $\mathrm{MoS}_{2}$, there should be more modification besides carbon coating and a nano-size design.

According to previous work on $\mathrm{MoS}_{2}, \mathrm{FeS}_{2}$ and $\mathrm{FeSe}_{2}$, setting an appropriate cut-off voltage to prevent a conversion type reaction happening is an effective way to improve the cycling life. ${ }^{23-25}$ Py et al. excluded the possibility for lithium/ electrolyte co-intercalation. ${ }^{26}$ After intercalating lithium there is only $0.14 \AA$ expansion of the $\mathrm{MoS}_{2}$ interlayer. The intercalation reaction can also confine the charge and discharge platform mainly locating in the voltage range of $1.5-2.0 \mathrm{~V}$, so this is a prominent improvement in the volume and voltage control of the intercalation reaction over the conversion type reaction. This inspires us to fabricate a full cell using $\mathrm{MoS}_{2}$ as the anode material mainly because of the low volume change and high terminal discharge voltage just like $\mathrm{Li}_{4} \mathrm{Ti}_{5} \mathrm{O}_{12}$, etc. ${ }^{16,27}$ As is 


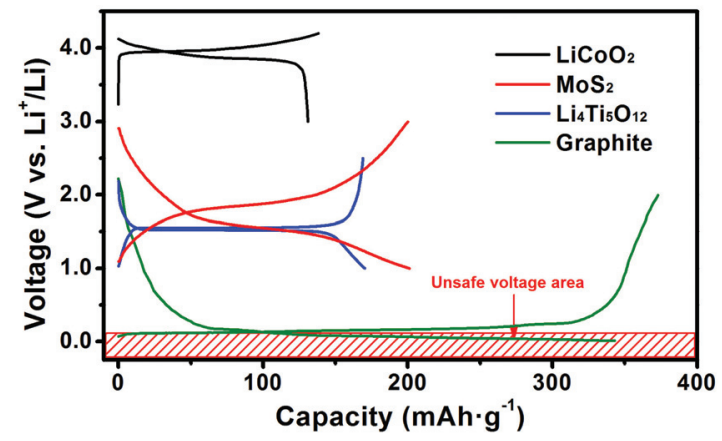

Fig. 1 The typical charge and discharge curves of $\mathrm{LiCoO}_{2}, \mathrm{MoS}_{2}$, $\mathrm{Li}_{4} \mathrm{Ti}_{5} \mathrm{O}_{12}$, and graphite.

known, high-voltage cathode materials (e.g. $\mathrm{LiCoO}_{2}$ and $\mathrm{LiNi}_{0.5} \mathrm{Mn}_{1.5} \mathrm{O}_{4}$ ) always suffer from the risk of electrolyte decomposition when charging over $4.0 \mathrm{~V}$ in practical use. Fig. 1 shows the typical charge and discharge curves of the cathode material $\mathrm{LiCoO}_{2}$, and anode materials $\mathrm{MoS}_{2}$, $\mathrm{Li}_{4} \mathrm{Ti}_{5} \mathrm{O}_{12}$, and graphite. Graphite is the most popular commercial anode material owing to its cheap price, relatively stable cyclability, and competitive specific capacity. However the charge and discharge curves are almost around $0 \mathrm{~V}$, which probably leads to the deposition of lithium metal on the surface of the anode materials and then causes severe safety issues like short circuiting. However, materials such as $\mathrm{MoS}_{2}$ and $\mathrm{Li}_{4} \mathrm{Ti}_{5} \mathrm{O}_{12}$, which have much safer voltage regions from 1.0-3.0 V (half cell), can not only avoid safety issues like short circuiting and large volume changes during cycling (full cell) but also lower the risk of electrolyte decomposition when serving as the counter electrode of high voltage cathode materials. ${ }^{14,28}$ Nevertheless, until now there are only a few papers focusing on $\mathrm{MoS}_{2} / \mathrm{Li}$ batteries with intercalation reactions. ${ }^{26,29-31}$

Herein we have synthesized $\mathrm{MoS}_{2}$ with expanded layers $\left(\mathrm{H}-\mathrm{MoS}_{2}\right)$ through a hydrothermal process and freeze-drying method by modifying the experimental method of our previous work. $^{23}$ To preserve the layer structure, obtain a relatively high specific capacity and protect the electrolyte from decomposition, the terminal discharge voltage was set to $1.0 \mathrm{~V}$. The stable charge and discharge platform was $\sim 1.8 \mathrm{~V}$ and $\sim 1.6 \mathrm{~V}$, which ensured possible applications in commercial rechargeable lithium batteries and as anodes in rechargeable LIBs (full cell with $\mathrm{LiCoO}_{2}$ as the counter electrode).

$\mathrm{H}-\mathrm{MoS}_{2}$ represents the product procured by hydrothermal treatment, and $\mathrm{B}-\mathrm{MoS}_{2}$ represents the bulk $\mathrm{MoS}_{2}$ purchased from Alfa Aesar (10-20 $\mu \mathrm{m})$. Fig. S1a† illustrates the X-ray diffraction (XRD) patterns of $\mathrm{H}-\mathrm{MoS}_{2}$ and $\mathrm{B}-\mathrm{MoS}_{2}$. The results show that the $\mathrm{H}-\mathrm{MoS}_{2}$ shows broadening characteristic peaks, and lower peak intensities. On the contrary, B-MoS 2 retains sharp and strong XRD peaks. Meanwhile the peak shift of the (002) crystal plane indicates that the layers in $\mathrm{H}-\mathrm{MoS}_{2}$ slightly expand. Fig. S1b and $\mathrm{S} 1 \mathrm{c} \dagger$ depict the high resolution transmission electron microscopy (HRTEM) images of $\mathrm{H}-\mathrm{MoS}_{2}$ and B-MoS ${ }_{2}$. The $d$-spacing calibrated from the crystal fringes is in accordance with the XRD analysis: the $\mathrm{H}-\mathrm{MoS}_{2}$ layers (layer dis- tance of $0.69 \mathrm{~nm}$ ) are in a disordered arrangement and are defect-rich, however B-MoS 2 possesses neatly restacked $\mathrm{MoS}_{2}$ layers with a $d$-spacing of $0.62 \mathrm{~nm}$. Through a freeze-drying process, which is also used as the most effective way to fabricate $2 \mathrm{D} / 3 \mathrm{D}$ graphene, the ice plays an important role in supporting the morphology. ${ }^{32}$ When the ice is removed from the powders, the $\mathrm{MoS}_{2}$ layers with expanded space could be preserved.

Then the electrochemical performances were tested using the ether-based electrolyte (1.0 M lithium bis(trifluoromethanesulfonyl)imide in tetraethylene glycol dimethyl ether). Fig. 2a and S2a $\uparrow$ exhibit the galvanostatic charge and discharge curves of $\mathrm{H}-\mathrm{MoS}_{2}$ and $\mathrm{B}-\mathrm{MoS}_{2}$ at $0.2 \mathrm{~A} \mathrm{~g}^{-1}$. Referring to the initial cycle, $\mathrm{H}-\mathrm{MoS}_{2}$ has a higher discharge platform $(\sim 1.5 \mathrm{~V})$ and more specific discharge capacity $\left(260 \mathrm{~mA} \mathrm{~h} \mathrm{~g}{ }^{-1}\right)$

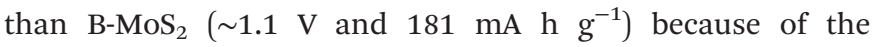
different $d$-spacing of (002). A larger layer distance facilitates the kinetics of $\mathrm{Li}^{+}$intercalation leading to a smaller energy barrier and more stable thermodynamics expressed as a stronger capacity for accommodating more $\mathrm{Li}^{+} .{ }^{33,34}$ From analysis of the cyclic data (Fig. $2 \mathrm{~b}$ and $\mathrm{S} 2 \mathrm{~b} \dagger$ ), the capacities of the 2 nd cycle reveal a slight decrease (the specific values are 195 and $108 \mathrm{~mA} \mathrm{~h} \mathrm{~g}{ }^{-1}$ for $\mathrm{H}-\mathrm{MoS}_{2}$ and $\mathrm{B}-\mathrm{MoS}_{2}$, respectively), which should be ascribed to the partial side reaction and the possibility of traces of residual $\mathrm{Li}^{+}$inside the layers. Then, the discharge capacity became a little higher (5-10 $\mathrm{mA} \mathrm{h} \mathrm{g}{ }^{-1}$ ), which is a result of the activation of the electrode materials. ${ }^{10}$ What's more, after the 1st cycle the charge and discharge curves change a bit. The mechanism of the 1st discharge process is well investigated. The phase conversion from $\operatorname{MoS}_{2}(2 \mathrm{H})$ to $\mathrm{MoS}_{2}(1 \mathrm{~T})$ should be the main reason for the curve changes. ${ }^{26}$ Fig. 2b reveals the cyclic performance of $\mathrm{H}-\mathrm{MoS}_{2}$. After the 1st cycle, the specific charge/discharge capacities are around $190 \mathrm{~mA} \mathrm{~h} \mathrm{~g}{ }^{-1}$. Then with gradual activation, the specific capacity remains stable at $205 \mathrm{~mA} \mathrm{~h} \mathrm{~g}^{-1}$ and after 1400 cycles
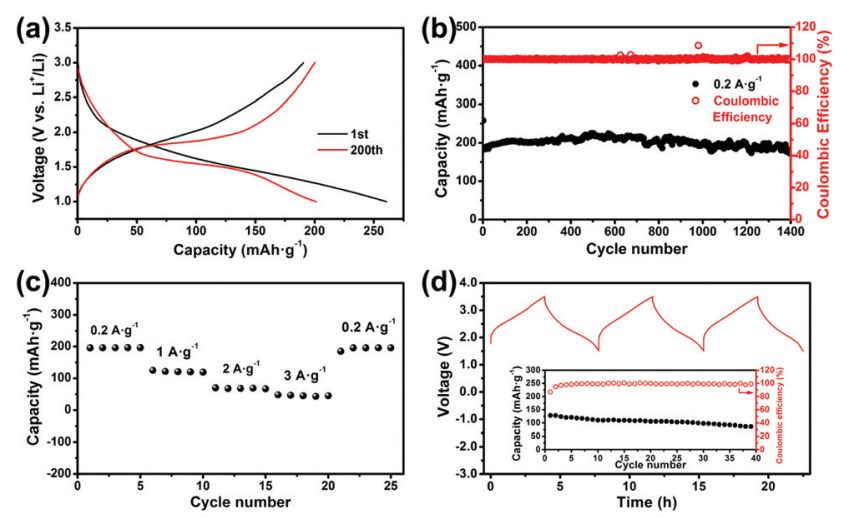

Fig. 2 Electrochemical performances of the as-prepared $\mathrm{MoS}_{2}$ and the full cell assembled by $\mathrm{LiCoO}_{2}$ with a cathode and $\mathrm{MoS}_{2}$ as an anode. (a) Galvanostatic charge and discharge curves of $\mathrm{MoS}_{2}$ at the 1st and 200th cycles at a current density of $0.2 \mathrm{~A} \mathrm{~g}^{-1}$. (b) Cyclic performance and (c) rate property of $\mathrm{MoS}_{2}$. (d) Galvanostatic charge and discharge curves of the full cell at the voltage range from 1.5-3.5 V (inset is the cyclic performance). 
the capacity retention is $96 \%$ (compared to the capacity of the second cycle). The coulombic efficiency has a low value in the 1st cycle (75\%), and then gradually increases to near $100 \%$ and is stable for 1400 cycles. Fig. 2c shows the rate property of $\mathrm{H}-\mathrm{MoS}_{2}$. The discharge capacities at $0.2,1,2$, and $3 \mathrm{~A} \mathrm{~g}^{-1}$ are 200, $115,70,50 \mathrm{~mA} \mathrm{~h} \mathrm{~g}{ }^{-1}$, respectively. $\mathrm{H}-\mathrm{MoS}_{2}$ displays a high capacity at a low current density $\left(0.2 \mathrm{~A} \mathrm{~g}^{-1}\right)$, and considerable capacity at 1 $\mathrm{A} \mathrm{g}^{-1}$. The $\mathrm{H}-\mathrm{MoS}_{2}$ battery can show a good recovery capability in high current density treatments: the discharge capacity can return back to $200 \mathrm{~mA} \mathrm{hg}^{-1}$ at $0.2 \mathrm{~A} \mathrm{~g}^{-1}$ after treating with $3 \mathrm{~A} \mathrm{~g}^{-1}$.

The half cell performance at $0.2 \mathrm{~A} \mathrm{~g}^{-1}$ in the voltage range of $0.1-3 \mathrm{~V}$ was also tested (Fig. S2c and S2d $\dagger$ ). As expected, the large voltage polarization between the charge and discharge process proves the above analysis that it is not suitable for full cell use. Although the discharge capacity can reach $670 \mathrm{~mA} \mathrm{~h}$ $\mathrm{g}^{-1}$ (4 electrons $/ \mathrm{Li}^{+}$ions reaction), the large volume change generated from the formation of the conversion products Mo and $\mathrm{Li}_{2} \mathrm{~S}$ leads capacity fade and worse reaction kinetics, which is proved by GITT characterization (Fig. S3 and S4 $\dagger$ ). It is clear that after the first discharge process, the $\mathrm{H}-\mathrm{MoS}_{2}$ battery cycling between 0.1-3.0 $\mathrm{V}$ shows sluggish ion diffusion (the lithium diffusion coefficient decreases by almost 1-2 orders of magnitude) leading to a large voltage polarization (Fig. S3b $\dagger$ ). However the $\mathrm{H}-\mathrm{MoS}_{2}$ battery cycling from 1.0 to $3.0 \mathrm{~V}$ possesses a fast lithium migration $\left(\sim 10^{-9} \mathrm{~cm}^{2} \mathrm{~s}^{-1}\right)$ ensuring the stable electrochemical performances mentioned above. An carbonate-based electrolyte (1M LiPF6 ethylene carbonate and diethyl carbonate) is used to investigate the influence of the electrolyte. As shown in Fig. S5, $\uparrow$ the $\mathrm{Li} / \mathrm{MoS}_{2}$ cell also performs well with good cycling stability. According to the above analysis, this means that the cutoff voltage is the most important factor for achieving long life.

To further investigate the possibility of using this material as an anode material, we have fabricated a full cell using $\mathrm{LiCoO}_{2}$ as the cathode material and $\mathrm{H}-\mathrm{MoS}_{2}$ as the anode material. The electrochemical performances of the assembled full cell are estimated using the active mass of the cathode material and are tested under $0.1 \mathrm{C}\left(14 \mathrm{~mA} \mathrm{~g}^{-1}\right)$. The galvanostatic charge and discharge curves are shown in Fig. 2d. The average charge platform is $\sim 2.80 \mathrm{~V}$ and average discharge platform is $\sim 2.35 \mathrm{~V}$. The slope of the discharge platform is convenient and accurate for the residual capacity indication. The cyclic data inserted in Fig. 2d shows that the 1st discharge capacity is $120 \mathrm{~mA} \mathrm{~h} \mathrm{~g}^{-1}$ with a coulombic efficiency of $82 \%$. Then the coulombic efficiency improves to near 99\% along with a capacity loss from 120 to $90.5 \mathrm{~mA} \mathrm{~h} \mathrm{~g}{ }^{-1}$. Analysis of a graphite/ $\mathrm{LiCoO}_{2}$ full cell is also performed (Fig. S6†). The charge and discharge platforms are at 4.0 and $3.6 \mathrm{~V}$, respectively and the discharge capacity is $132 \mathrm{~mA} \mathrm{~h} \mathrm{~g}^{-1}$. After cycling 30 times, the capacity retention is $91.6 \%$. Thus the performance of the $\mathrm{MoS}_{2} /$ $\mathrm{LiCoO}_{2}$ battery is comparable with that of a commercial type graphite/LiCoO $\mathrm{L}_{2}$ battery, and moreover $\mathrm{MoS}_{2}$ possesses a higher safety factor because of its high charge and discharge voltage region (Fig. 1). The full cell technology should be improved in further investigations such as by designing high tapping density $\mathrm{MoS}_{2}$ with high electrochemical performances. However this result shows the possibility of using $\mathrm{MoS}_{2}$ as an anode material for LIBs.
The electrochemical impedance spectroscopy (EIS) measurements of $\mathrm{H}-\mathrm{MoS}_{2}$ at different voltage ranges were also characterized (Fig. S7 $\dagger$ ). Both EIS data from 1.0-3.0 V and 0.1-3.0 $\mathrm{V}$ exhibit one circle at high frequency and a line at low frequency. By comparing the different voltage ranges, the charge transfer resistance of the intercalation reaction is much smaller than that of the conversion reaction. Moreover $\mathrm{H}-\mathrm{MoS}_{2}$ shows smaller charge transfer resistance than $\mathrm{B}-\mathrm{MoS}_{2}$, resulting from the better nano-design that facilitates the electrochemical reaction kinetics.

Fig. 3 shows further investigations of the electrode material after cycling. Transmission electron microscopy (TEM) and HRTEM images of the $\mathrm{MoS}_{2}$ electrode after cycling 100 times are shown in Fig. 3a and b. It is noticed that the graphite (conductive additive, KS-6) served as the carrier for the $\mathrm{MoS}_{2}$ particles and as the conductive substrate between the collector and $\mathrm{MoS}_{2}$ particles. We also find the $\mathrm{MoS}_{2}$ layers preserved after cycling, which means that the conversion reaction does not happen when the terminal discharge voltage is set to $1.0 \mathrm{~V}$. Energy dispersive X-ray spectroscopy (EDX) measurement was also employed to detect the elemental content of Mo and S. The results show that the atomic ratio of Mo versus $\mathrm{S}$ is about $1: 2$, however there is a loss of $\mathrm{S}$ of about $2 \%$, which should be ascribed to systematic error and a partial over-discharge effect. Fig. 3d shows the electrode material after cycling 10 times in the voltage range of 0.1-3.0 V. Apparently nano-sized Mo particles are detected and found to be a little aggregated, which would cause separation of Mo and $\mathrm{Li}_{2} \mathrm{~S}$ leading to a severe capacity loss. ${ }^{16}$

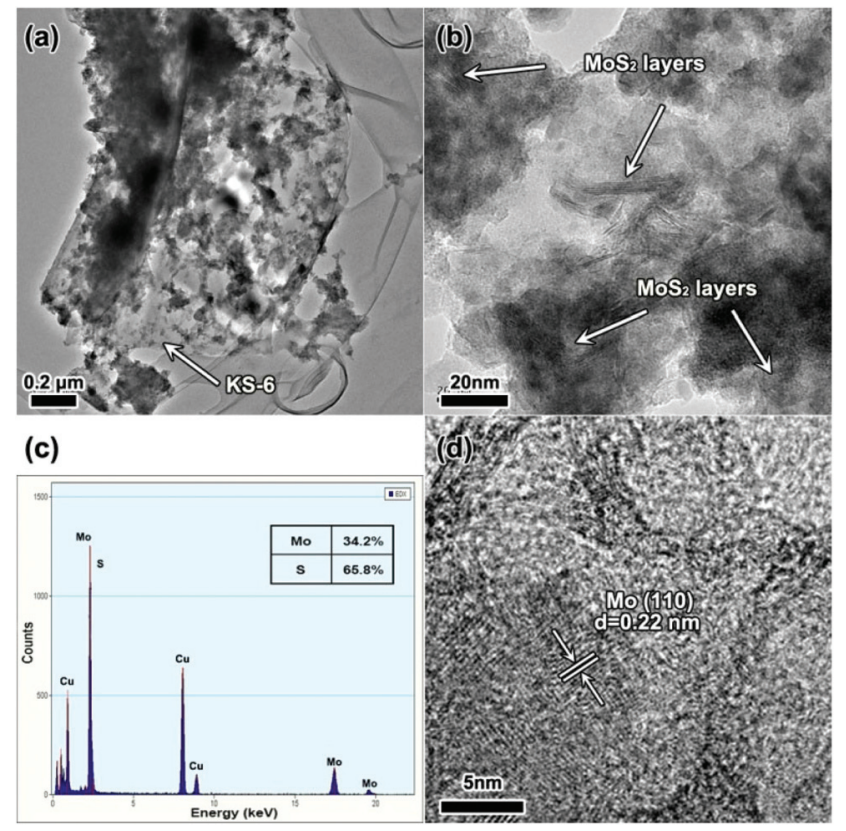

Fig. 3 TEM characterization of the electrode material (half cell) after cycling. (a) The TEM image, (b) HRTEM image, and (c) EDX of the MoS electrode at $1.0 \mathrm{~V}$ after cycling between $1.0 \mathrm{~V}$ and $3.0 \mathrm{~V} 100$ times. (d) HRTEM image of the $\mathrm{MoS}_{2}$ electrode at $0.1 \mathrm{~V}$ after cycling at $0.1-3.0 \mathrm{~V}$ 10 times. 
The overall characterization and discussion connect the proof of the excellent electrochemical properties of $\mathrm{H}-\mathrm{MoS}_{2}$ cycling in 1.0-3.0 V. Expanded layers provide better thermodynamics and kinetics, expressed as a higher discharge voltage and fast ionic conductivity. By eliminating the conversion reaction, the wholly preserved layer-structured $\mathrm{MoS}_{2}$ ensures a rechargeable ability for $\mathrm{MoS}_{2} / \mathrm{Li}$ and $\mathrm{LiCoO}_{2} / \mathrm{MoS}_{2}$ batteries. A smaller charge transfer resistance reveals improved kinetics leading to a smaller voltage polarization.

\section{Conclusions}

The as-prepared $\mathrm{MoS}_{2}$ was synthesized through a hydrothermal process. By cutting off the terminal discharge voltage to $1.0 \mathrm{~V}$ in an ether-based electrolyte, $\mathrm{H}-\mathrm{MoS}_{2}$ exhibits a high discharge capacity of $200 \mathrm{~mA} \mathrm{~h} \mathrm{~g}^{-1}$ at $0.2 \mathrm{~A} \mathrm{~g}^{-1}$ with a stable charge and discharge platform of $\sim 1.8 \mathrm{~V}$ and $\sim 1.6 \mathrm{~V}$, respectively. Regarding the cyclability, it can cycle 1400 times with almost no capacity fade. Thus controlling the terminal discharge voltage should be an effective way to improve conversion type materials with two key factors; an intercalation process that occurs before the conversion reaction happens, and easy-control voltage management. More attention should focus on the intercalation reaction so that $\mathrm{MoS}_{2}$ can finally find promising applications as an anode material for rechargeable lithium ion batteries.

\section{Acknowledgements}

This work is financially supported by the Australian Research Council (ARC) through a Linkage Project (LP120200432) and the Commonwealth of Australia through the Automotive Australia 2020 Cooperative Research Centre (Auto CRC). The authors acknowledge use of the facilities at the UOW Electron Microscopy Centre funded by ARC grants (LE0882813 and LE0237478). The authors would also like to thank Dr Tania Silver for the critical reading of the manuscript.

\section{Notes and references}

1 B. Dunn, H. Kamath and J.-M. Tarascon, Science, 2011, 334, 928-935.

2 K. Kang, Y. S. Meng, J. Bréger, C. P. Grey and G. Ceder, Science, 2006, 311, 977-980.

3 H. J. Yu, Y. Ren, D. D. Xiao, S. H. Guo, Y. B. Zhu, Y. M. Qian, L. Gu and H. S. Zhou, Angew. Chem., Int. Ed., 2014, 53, 8963-8969.

4 Y. Sun, J. Zhu, L. Bai, Q. Li, X. Zhang, W. Tong and Y. Xie, Inorg. Chem. Front., 2014, 1, 58-64.

5 S. Xu, S. Lau and L. A. Archer, Inorg. Chem. Front., 2015, 2, 1070-1079.

6 J. Zhou, J. Qin, X. Zhang, C. Shi, E. Liu, J. Li, N. Zhao and C. He, ACS Nano, 2015, 9, 3837-3848.

7 R. Tenne, Nat. Nanotechnol., 2006, 1, 103-111.
8 X. Huang, Z. Y. Zeng and H. Zhang, Chem. Soc. Rev., 2013, 42, 1934-1946.

9 X. Cao, Y. Shi, W. Shi, X. Rui, Q. Yan, J. Kong and H. Zhang, Small, 2013, 9, 3433-3438.

10 H. Hwang, H. Kim and J. Cho, Nano Lett., 2011, 11, 48264830.

11 K. Chang and W. X. Chen, J. Mater. Chem., 2011, 21, 1717517184.

12 J. Xiao, X. J. Wang, X. Q. Yang, S. D. Xun, G. Liu, P. K. Koech, J. Liu and J. P. Lemmon, Adv. Funct. Mater., 2011, 21, 2840-2846.

13 P. Sun, W. Zhang, X. Hu, L. Yuan and Y. Huang, J. Mater. Chem. A, 2014, 2, 3498-3504.

14 Z. Wu, B. Li, Y. Xue, J. Li, Y. Zhang and F. Gao, J. Mater. Chem. A, 2015, 3, 19445-19454.

15 Y. Gong, S. Yang, Z. Liu, L. Ma, R. Vajtai and P. M. Ajayan, Adv. Mater., 2013, 25, 3979-3984.

16 T. Stephenson, Z. Li, B. Olsen and D. Mitlin, Energy Environ. Sci., 2014, 7, 209-231.

17 Y. X. Wang, S. L. Chou, D. Wexler, H. K. Liu and S. X. Dou, Chem. - Eur. J., 2014, 20, 9607-9612.

18 H. Liu, D. Su, R. Zhou, B. Sun, G. Wang and S. Z. Qiao, Adv. Energy Mater., 2012, 2, 970-975.

19 J. Gao, M. A. Lowe, Y. Kiya and H. D. Abruña, J. Phys. Chem. C, 2011, 115, 25132-25137.

20 Y.-X. Yin, S. Xin, Y.-G. Guo and L.-J. Wan, Angew. Chem., Int. Ed., 2013, 52, 13186-13200.

21 C. B. Zhu, X. K. Mu, P. A. van Aken, Y. Yu and J. Maier, Angew. Chem., Int. Ed., 2014, 53, 2152-2156.

22 K. Zhang, X. Han, Z. Hu, X. Zhang, Z. Tao and J. Chen, Chem. Soc. Rev., 2015, 44, 699-728.

23 Z. Hu, L. Wang, K. Zhang, J. Wang, F. Cheng, Z. Tao and J. Chen, Angew. Chem., Int. Ed., 2014, 53, 1279412798.

24 Z. Hu, Z. Zhu, F. Cheng, K. Zhang, J. Wang, C. Chen and J. Chen, Energy Environ. Sci., 2015, 8, 1309-1316.

25 K. Zhang, Z. Hu, X. Liu, Z. Tao and J. Chen, Adv. Mater., 2015, 27, 3305-3309.

26 M. A. Py and R. R. Haering, Can. J. Phys., 1983, 61, 76-84.

27 Z. Hu, K. Zhang, Z. Zhu, Z. Tao and J. Chen, J. Mater. Chem. A, 2015, 3, 12898-12904.

28 Z. Zhu, F. Cheng and J. Chen, J. Mater. Chem. A, 2013, 1, 9484-9490.

29 N. Imanishi, K. Kanamura and Z. i. Takehara, J. Electrochem. Soc., 1992, 139, 2082-2087.

30 C. Julien, S. I. Saikh and G. A. Nazri, Mater. Sci. Eng., B, 1992, 15, 73-77.

31 Y. Miki, D. Nakazato, H. Ikuta, T. Uchida and M. Wakihara, J. Power Sources, 1995, 54, 508-510.

32 L. Qian and H. Zhang, J. Chem. Technol. Biotechnol., 2011, 86, 172-184.

33 K. Chang, W. Chen, L. Ma, H. Li, H. Li, F. Huang, Z. Xu, Q. Zhang and J.-Y. Lee, J. Mater. Chem., 2011, 21, 62516257.

34 S. Q. Yang, D. X. Li, T. R. Zhang, Z. L. Tao and J. Chen, J. Phys. Chem. C, 2011, 116, 1307-1312. 